\title{
Mudanças na vida quotidiana em pessoas idosas institucionalizadas pelo impacto da doença
}

\section{Changes in daily life in institutionalized older adults caused by the impact of the disease}

\author{
Nuno de Noronha da Costa Bispo (1) \\ Viviane de Souza Pinho Costa (2) \\ Mario Molari (1) \\ Letícia Caroline Falossi (2) \\ Tatiani Aparecida Silva Fidelis (3) \\ Fernanda Freitas Gonçalves (3) \\ Thainara Ferreira Furini (4) \\ Flamínia Manzano Moreira Lodovici (5) \\ Ruth Gelehrter da Costa Lopes (5) \\ Maria Helena Villas Boas Concone (5) \\ (1) Univ Pitágoras Unopar, Londrina, Brasil \\ (2) Pontifícia Univ Católica Paraná, Londrina, Brasil \\ (3) Univ Estad Londrina, Brasil \\ (4) Clín Renovar Vida, Londrina, Brasil \\ (5) Pontifícia Univ Católica São Paulo, Brasil
}

Recebido: 13/03/2020; Revisto: 14/04/2020; Aceite: 10/05/2020.

https://doi.org/10.31211/rpics.2020.6.1.169

\section{Resumo}

Objetivo: Verificar as mudanças na vida cotidiana em pessoas idosas institucionalizadas provocadas pelo impacto da doença foi o objetivo geral desta pesquisa etnográfica. Método: A pesquisa decorreu com 99 residentes de uma instituição de longa permanência para idosos, no sul do Brasil. Houve uma pesquisa documental da Instituição e a permanência do pesquisador para a familiarização deste com o ambiente e todo o público. A observação participante e a entrevista semiestruturada foram utilizadas para a coleta de dados. Após o trabalho de campo, os dados foram analisados por meio da descrição da observação e pelo método hermenêutico-dialético. Resultados: observou-se a dependência funcional, perda da autonomia e do controle pessoal. Nas falas dos participantes, constatou-se a perda da liberdade, a dependência física nas atividades do cotidiano, a diminuição da ocupação, o isolamento e a dificuldade para dormir. $\mathrm{O}$ acometimento da mobilidade foi notado na observação participante e nas entrevistas. Conclusão: Nas considerações finais a temática da pesquisa qualitativa destaca a restrição da autonomia que as pessoas idosas residentes da Instituição enfrentam diante às novas condições vivenciadas no quotidiano institucional ocasionado pela doença, o que interfere na qualidade de vida destes residentes.

Palavras-Chave: Doença; Pessoas idosas; Instituição de Longa Permanência para Idosos.

\section{DI\&D | ISMT}

rpics@ismt.pt https://rpics.ismt.pt
Publicação em Acesso Aberto

(C)2020. O(s) Autor(es). Este é um artigo de acesso aberto distribuído sob a Licença Creative Commons Attribution, que permite uso, distribuição e reprodução sem restrições em qualquer meio, desde que o trabalho original seja devidamente citado.
Nuno Bispo

R. Fermino Barbosa, 148, casa 09, Bairro Aurora, CEP.: 86.047-480, Londrina/Paraná, Brasil. E-mail: nunofisio@hotmail.com 


\begin{abstract}
Objective: To verify the changes in daily life in institutionalized older adults caused by the impact of the disease, was the general objective of this ethnographic research. Method: The study was carried out with 99 residents of a long-term care institution for the elderly in southern Brazil. There was documentary research of the Institution and the permanence of the researcher to familiarize him with the environment and the entire public. Participant observation and semi-structured interviews were used for data collection. After the fieldwork, the data were analyzed through the description of the observation and the hermeneuticdialectic method. Results: The results showed functional dependence, loss of autonomy, and personal control. Based on the participants' comments, the study detected a lack of freedom, physical dependence to carry out routine activities, occupation reduction, isolation, and difficulty to sleep. The impairment of mobility was noted in the participant observation and the interviews. Conclusion: In the final remarks, the issue of qualitative research highlights the restriction of autonomy that older people are residing in the Institution in the face of the new conditions experienced in institutional life caused by the disease, which interferes with the quality of life of these residents.
\end{abstract}

Keywords: Disease; older people; Long-term care institution for older adults.

\title{
Introdução
}

A vida quotidiana é o lugar onde o indivíduo "se sente protegido no seio de uma trama sólida de hábitos e de rotinas que ele criou para si com o tempo, de percursos bem conhecidos, cercados de rostos familiares" (Le Breton, 2003/2011, p. 142).

As rotinas acontecem durante o quotidiano, onde as pessoas têm uma "repetição de padrões semelhantes de comportamento" (Giddens, 2009/2012, p. 188). As rotinas são eventos previsíveis que fornecem uma base para as tarefas diárias na vida de uma pessoa (Gillespie \& Petersen, 2012). Tornam o desenvolvimento das distintas "sequências da vida" cada vez mais automáticas devido aos gestos, sensações e percepções que encorpam o indivíduo" (Le Breton, 2003/2011, p. 142). Durante todos os dias as atividades realizadas rotineiramente são idênticas, a não ser que apareça algum evento diferente, que faça a pessoa mudar sua trajetória, mas logo que termine, a rotina volta ao que era anteriormente (Giddens, 2009/2012).

As interações sociais que também ocorrem durante o quotidiano, praticamente todos os dias e muitas vezes em um único dia, é a maneira pelas quais as pessoas agem com outras pessoas e reagem à forma como as outras pessoas estão agindo (Barkan, 2012).

A vida quotidiana é marcada pelos eventos decorridos durante a passagem do tempo, mas o tempo vai passando lentamente e despercebido na consciência das pessoas (Le Breton, 2003/2011). Nesta passagem do tempo, vai acontecendo gradualmente o processo de envelhecimento:

Um processo insensível, infinitamente lento, que escapa à consciência porque nele nenhum contraste acontece, o homem desliza flexivelmente de um dia ao outro, de uma semana à outra, de um ano ao outro, são eventos de sua vida quotidiana que pontuam o fluxo do dia, e não a consciência do tempo. Com uma lentidão que escapa ao entendimento, a duração se agrega sobre o rosto, penetra os tecidos, enfraquece os músculos, ameniza a energia, mas sem traumatismos, sem ruptura brutal (Le Breton, 2003/2011, pp. 228229).

Mas pode surgir algum acontecimento maior que mude as rotinas da vida quotidiana, como por exemplo, a mudança de emprego, a aposentadoria, a institucionalização e até mesmo a doença (Giddens, 2009/2012). 
A doença é uma "experiência subjetiva interna do indivíduo que está consciente de que o bem-estar pessoal foi ameaçado e como a pessoa responde a essa experiência" (Guccione, 2000/2002, p. 106). A experiência humana de sintomas e sofrimento alude à forma como a doença é percebida, vivida, e respondida pelos indivíduos e suas famílias (Larsen, 2013b).

A doença crónica é precisamente um tipo de experiência, onde as estruturas da vida quotidiana são interrompidas (Bury, 1982). De acordo com o autor, envolve um reconhecimento dos mundos de dor e sofrimento, possivelmente até mesmo da morte, que são normalmente vistos como possibilidades distantes ou do sofrimento dos outros. Todos esses efeitos ou transformações experienciadas pelas pessoas acometidas por doença de longa duração, são entendidas como o impacto da doença, que modifica a realidade de cada pessoa (Barsaglini \& Soares, 2018). A presença de uma doença crónica altera significativamente o comportamento quotidiano, gerando muita incapacidade e necessidade de cuidados médicos constantes e, talvez até mais importante, uma diminuição na qualidade e plenitude da vida (Royer, 1998).

Cada indivíduo desempenha determinadas funções e tarefas no ambiente onde vive. A capacidade e a incapacidade das pessoas podem ser plenamente compreendidas e estimadas apenas em termos do grau do seu comprometimento destas funções e tarefas. Quando um indivíduo é descrito como sendo "incapaz", a descrição é incompleta, até que se responde à pergunta, "incapaz de fazer o quê?" (Nagi, 1964).

Segundo Hayflick (2007), durante o processo de envelhecimento, ocorrem alterações moleculares, deixando o organismo das pessoas mais vulneráveis às doenças. Essa vulnerabilidade mostra-se acentuada na população idosa, sendo a questão saúde um componente importante no perfil desta faixa etária (Sugahara, 2005) necessitando de cuidados sociais e de saúde, realizados por profissionais em ambientes adequados (Meire, 2000). Geralmente, as pessoas idosas nestas condições, são encaminhadas para as instituições de longa permanência para idosos (ILPIs), tendo como característica a fragilidade, as deficiências múltiplas, as doenças incapacitantes e a dependência (Dramé et al., 2004).

Neste panorama, o objetivo desta pesquisa etnográfica, foi verificar as mudanças na vida quotidiana em pessoas idosas institucionalizadas pelo impacto da doença.

\section{Método}

\section{Desenho do Estudo}

O enfoque qualitativo foi selecionado para compreender a perspetiva dos participantes sobre os fenómenos que os rodeiam, aprofundando em suas experiências, pontos de vista, opiniões e significados, isto é, a forma como os participantes percebem subjetivamente sua realidade (Sampieri et al., 2013). Nesta pesquisa optou-se pela etnografia, para estudar as interações sociais, comportamentos e perceções que ocorreram num grupo de pessoas, onde o pesquisador coletou informações participando do quotidiano deste grupo (Reeves \& Hodges, 2008). Em seus estudos sobre a pesquisa etnográfica, Hammersley (2018) fez uma lista das características principais:

O processo de coleta de dados é feito num período longo, ocorre em ambientes naturais, conta com a observação participante ou outros métodos onde há envolvimento pessoal mais geral, emprega uma variedade de dados, documenta realmente o que acontece e enfatiza a importância dos significados que as pessoas dão aos objetos, incluindo a si próprios, no curso de suas atividades (p. 4). 
Na etnografia, o pesquisador estuda um grupo que compartilha a mesma cultura, "mergulhando" na vida quotidiana das pessoas (Creswell, 2012/2014), lançando mão da observação participante e entrevistas, que podem ser estruturadas ou não (Hammersley \& Atkinson, 2007; Kottak, 2012/2013). “As estratégias metodológicas aplicadas no campo em estudo ainda baseiam-se muito na observação daquilo que está acontecendo no campo por meio da participação neste" (Flick, 2009, p. 215). “A observação participante proporciona o grande diferencial da pesquisa etnográfica, por propor a imersão do pesquisador no modo de vida dos pesquisados, fugindo assim dos ambientes artificiais de laboratórios", bem como as entrevistas serem uma alternativa para "entender a versão dos entrevistados sobre seus próprios mundos" (Martins \& Theóphilo, 2009). Atualmente, neste tipo de pesquisa, "os etnógrafos podem adotar uma estratégia ampla e livre de coleta de informações", pela diversidade de técnicas que têm à disposição (Kottak, 2012/2013). Sobre a etnografia, Mattos (2011) acrescenta:

É um processo guiado preponderantemente pelo senso questionador do etnógrafo. Deste modo, a utilização de técnicas e procedimentos etnográficos, não segue padrões rígidos ou pré-determinados, mas sim, o senso que o etnógrafo desenvolve a partir do trabalho de campo no contexto social da pesquisa (p. 50).

Hammersley e Atkinson (2007) afirmam que a análise dos dados envolve a interpretação dos significados, funções e consequências das ações humanas e das práticas institucionais, e como elas estão implicadas em contextos locais. Além de ser conhecida pela observação participante, a etnografia também é vista como pesquisa interpretativa ou hermenêutica, por estudar grupos de pessoas que são associadas de alguma maneira (Mattos, 2011). Como exemplo, podemos citar idosos residentes em uma instituição, que é o caso desta pesquisa.

Através dos tempos, a etnografia vem sofrendo diversas modificações, e defini-la, é um grande desafio devido à falta de consenso nos debates entre os etnógrafos (Hammersley, 2018).

\section{Participantes}

Esta pesquisa foi realizada em uma Instituição de Longa Permanência para Idosos em uma cidade do sul do Brasil, com 99 residentes. O principal critério de seleção do estudo, era ter idade de 60 anos ou mais. $\mathrm{Na}$ observação participante foram incluídos no estudo 96 residentes e três foram excluídos por ter idade inferior a 60 anos. Para as entrevistas, os critérios de seleção foram os seguintes: não apresentar distúrbios de comunicação e ter o funcionamento cognitivo preservado para conseguir responder às perguntas do roteiro. Neste último caso, foi consultado o Mini-Exame do Estado Mental (Folstein et al., 1975) no processo de saúde dos participantes. Portanto, foram selecionadas 37 pessoas (Figura 1).

\section{Procedimentos}

\section{Considerações Éticas}

Para não identificar os participantes das entrevistas, os nomes foram substituídos e codificados pela letra "E" (de entrevistado) e, por um número, pela ordem da entrevista. Deste modo, os participantes foram identificados, como explica o exemplo a seguir: E1, E2, E3 ... E37. Garantiu-se o sigilo não só quanto à preservação do nome dos participantes, mas também de outras informações ou dados que pela sua natureza 
pudessem levar ao reconhecimento do participante pelo grupo social. Apresentou-se a cada participante, um termo de consentimento livre e esclarecido (TCLE) e à Instituição de Longa Permanência para Idosos, um pedido de autorização. Este projeto de pesquisa também foi aprovado pelo Comité de Ética da Pontifícia Universidade Católica de São Paulo, através da Plataforma Brasil sob o número CAAE 10829212.2.0000.5482.

\section{Figura 1}

Fluxograma da Metodologia da Pesquisa

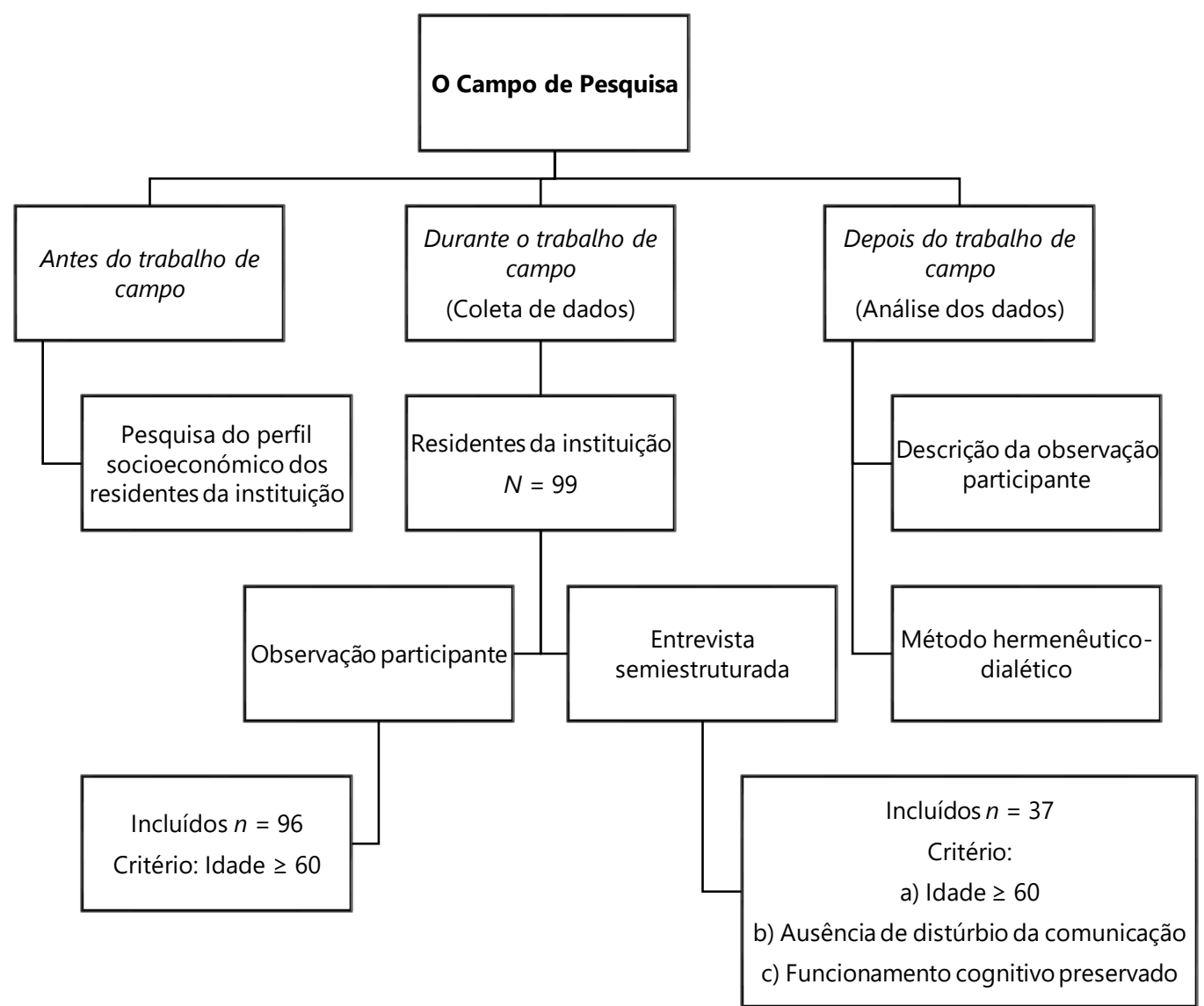

\section{O Campo de Pesquisa}

Procuramos descrever as ações metodológicas realizadas antes, durante e após o trabalho de campo (Figura 1). Mas antes dessa descrição, apresentamos uma definição sobre trabalho de campo elaborada por Pole e Hillyard (2016):

É uma maneira de fazer pesquisa onde a ênfase é colocada sobre a coleta de dados, depende da interação entre o pesquisador e os participantes no ambiente de pesquisa, bem como é usado uma combinação de métodos para coletar dados durante um período prolongado de tempo (p. 3).

Antes do Trabalho de Campo. Realizou-se um levantamento documental sobre os residentes (características físicas, sociais, institucionalização e moradia antes da institucionalização) e sobre a instituição (estrutura física e social). 
Durante o Trabalho de Campo. Na coleta de dados, optou-se pela observação participante e pela entrevista não estruturada. A junção destes dois métodos para estudar a experiência da doença enfatiza uma compreensão detalhada dos aspetos sociais ou coletivos de experiência, além dos aspetos pessoais (Calabrese, 2013). A observação participante e as entrevistas foram realizadas pelo autor principal.

"A observação participante, que significa que tomamos parte na vida da comunidade ao estuda-la" (Kottak, 2012/2013, p. 72). O pesquisador envolve-se na vida e atividades diárias de uma determinada comunidade, observando relacionamentos, a interação social e a vida comunitária (Calabrese, 2013). Segundo Kottak (2012/2013, p. 72), "também participa de diversos eventos e processos que observa e tenta compreende-los, permitindo saber por que as pessoas consideram esses eventos significativos, pois vemos como eles são organizados e realizados". Durante um ano, diariamente no período matutino e vespertino, a observação foi realizada no decorrer das atividades académicas da universidade na instituição, propiciando a interação com os indivíduos que foram objeto de estudo. Por isso adotou-se a técnica de "Observação Participante como observador", ou seja, o pesquisador está envolvido com os participantes num tempo mais reduzido e em algumas atividades (Creswel, 2014, p. 137).

Para facilitar e realizar uma observação mais organizada, optou-se pelo processo preconizado por Spradley (1980), composto por três fases:

1. A primeira fase denomina-se observação descritiva: Tem a finalidade de obter uma visão geral da situação social, que abrange o lugar, as pessoas e as atividades realizadas no quotidiano. Fornece ao pesquisador uma orientação para o campo de estudo (Flick, 2009).

2. A segunda fase é a observação focalizada: direciona o pesquisador para os aspetos essenciais para a questão da pesquisa, neste caso, a observação da vida quotidiana dos participantes.

3. A terceira fase composta pela observação seletiva: é a fase final da coleta neste método, onde se direciona e especifica mais ainda, tentando encontrar mais indícios para os objetivos da pesquisa, que neste caso seria observar a interferência da doença na vida quotidiana dos idosos.

Através da entrevista semiestruturada, seguiu-se a estratégia utilizada na pesquisa de Kottak (2012/2013), que consistiu num roteiro que continha um conjunto central de perguntas: I. O Sr(a) tem alguma doença? Como se sente? II. Como a doença interfere (atrapalha) na sua vida cotidiana? III. O que deixou de fazer por causa da doença? IV. O que gostaria de fazer se não tivesse doente? Conforme decorria a entrevista, surgiam algumas questões paralelas interessantes, que eram abordadas em seguida ou no final.

O registo da entrevista foi feito com um aparelho MP4, onde o microfone é embutido permitindo que a gravação seja clara suficientemente e, posteriormente transferida para um arquivo no computador. 0 tempo médio das entrevistas foi de 10 minutos.

Depois do Trabalho de Campo. Realizou-se a análise dos dados: primeiro fez-se da observação participante e depois das entrevistas. Na observação participante realizou-se a descrição e explicação da observação da "situação social", ou seja, do comportamento ou atividades das pessoas em um determinado local (Spradley, 1980), esta análise constitui-se de duas fases: a primeira de uma descrição geral do ambiente físico (as características do espaço frequentado pelos idosos) e a outra, do ambiente social (a forma de viver dos residentes e o seu quotidiano).

Para as entrevistas utilizou-se a técnica hermenêutico-dialética, proposta por Minayo (2007), onde o conjunto destas duas palavras que determina o entendimento de uma fala ou de um depoimento. Na pesquisa adotaram- 
se os seguintes passos preconizados por Minayo (2007) na execução dos dados, ou seja, no instante hermenêutico:

1. Ordenação dos dados: Esta fase compreende o mapeamento de todos os dados obtidos pela entrevista, que incluiu a transcrição das gravações, a releitura dos textos e a organização dos relatos numa determinada ordem.

2. Classificação dos dados: Neste momento os dados são embasados com a fundamentação teórica. Esta fase pode ser dividida em duas etapas. A primeira consiste numa "leitura flutuante" ou "leitura horizontal", constituída por leitura extenuante, minuciosa e redobrada das transcrições de cada entrevista, para compreender as ideias centrais que transmitem os pontos-chave do tema do trabalho. Na segunda etapa, realiza-se uma "leitura transversal" de cada texto transcrito e realizado o "recorte de cada entrevista" em "unidades de significado" e, em seguida, referenciada por assunto. Depois disto, opera-se uma seleção dos temas mais relevantes que evidenciaram as hipóteses do trabalho.

3. Análise final: Nesta fase, responde-se às questões da pesquisa com base nos seus objetivos.

\section{Resultados e Discussão}

Em relação ao levantamento documental sobre os residentes da instituição, na Tabela 1 está representado o perfil sociodemográfico da instituição. Sobre a institucionalização, 46 pessoas moravam há mais de seis anos na instituição; 48 pelo motivo de cuidados de saúde. Quanto ao responsável pelo encaminhamento, 34 foi por um familiar, 15 por outras instituições, 12 por denúncia e os outros 38 foram encaminhados por projetos da prefeitura, unidades básicas de saúde, ou por outras pessoas. Antes da institucionalização, moravam sozinhos na zona urbana.

\section{Observação Participante}

Para os resultados da observação participante, descrevemos primeiramente algumas características da estrutura física e social da instituição e posteriormente a vida quotidiana dos residentes.

A instituição é formada por duas alas, 1 e 2. A Ala 1 apresenta-se logo à entrada do asilo com um jardim à sua frente e um arvoredo numa das laterais, que o separa da creche e da paróquia. Atrás desta ala, fica a Ala 2, ou ala São José, ainda conhecida como "enfermaria". Entre as duas alas, aparece outro jardim e, nas laterais deste encontram-se: num lado a barbearia, a sala de atividades manuais (antiga lavandaria) e uma garagem; no outro lado, o bazar. Numa das laterais da enfermaria existe um gramado que corre em toda a extensão do edifício. Na outra lateral está uma ruazinha que, quando se atravessa, vai dar também a um gramado acompanhando também toda essa lateral.

Como todas as ILPIs, esta instituição também tem uma rotina diária, com horários e uma sequência das atividades diárias que seguem uma organização e um planeamento. O quotidiano dos residentes constitui-se em seguir a rotina diária da instituição, que inclui as seguintes atividades: banho, café da manhã, almoço, lanche da tarde, jantar, ceia, cuidados de enfermagem, medicamentos, fisioterapia, terapia ocupacional, educação física, serviço social, atendimento psicológico, aulas de alfabetização, atividade física, missa semanal e passeios. Esta rotina do quotidiano pode ser interrompida em algum momento, quando surge algum evento promovido pela instituição ou por outras entidades. 


\section{Tabela 1}

Perfil Sociodemográfico da Instituição ( $\mathrm{N}=99)$

\begin{tabular}{|c|c|c|c|}
\hline & & $n$ & $\%$ \\
\hline \multirow{5}{*}{ Idade } & $\leq 59$ & 3 & 3,0 \\
\hline & $60-69$ & 22 & 22,2 \\
\hline & 70-79 & 46 & 46,5 \\
\hline & $80-89$ & 20 & 20,2 \\
\hline & $\geq 90$ & 8 & 8,1 \\
\hline \multirow{2}{*}{ Sexo } & Feminino & 41 & 41,4 \\
\hline & Masculino & 58 & 58,6 \\
\hline \multirow{4}{*}{ Raça } & Branca & 62 & 62,6 \\
\hline & Parda & 18 & 18,2 \\
\hline & Negra & 17 & 17,2 \\
\hline & Amarela & 2 & 2,0 \\
\hline \multirow{5}{*}{ Estado Civil } & Solteiro & 51 & 51,5 \\
\hline & Viúvo & 20 & 20,2 \\
\hline & Separado & 14 & 14,1 \\
\hline & Divorciado & 7 & 7,1 \\
\hline & Casado & 7 & 7,1 \\
\hline \multirow{7}{*}{ Número de filhos } & Nenhum & 47 & 47,5 \\
\hline & 1 & 16 & 16,2 \\
\hline & 2 & 8 & 8,1 \\
\hline & 3 & 8 & 8,1 \\
\hline & 4 & 5 & 5,1 \\
\hline & + de 4 & 4 & 4,0 \\
\hline & Sem registo & 11 & 11,1 \\
\hline \multirow{2}{*}{ Escolaridade } & Alfabetizado & 42 & 42,4 \\
\hline & Não alfabetizado & 57 & 57,6 \\
\hline \multirow{4}{*}{ Religião } & Católica & 72 & 72,7 \\
\hline & Evangélica & 9 & 9,1 \\
\hline & Outras religiões & 2 & 2,0 \\
\hline & Sem dados & 16 & 16,2 \\
\hline Renda* & 1 salário mínimo & 99 & 100 \\
\hline
\end{tabular}

Nota. *Aposentadoria ou benefício por invalidez

Na Ala 1 os idosos são mais independentes e autónomos, têm mais facilidade em realizar as atividades quotidianas, poucos precisam de supervisão para realizar as atividades básicas da vida diária e alguns ajudam em determinadas atividades no asilo, tais como: passar a roupa, levar a roupa da rouparia para o banheiro, descascar algumas verduras e frutas, levar alguns recados, passear com as pessoas em cadeiras de roda, visitas aos idosos debilitados da Ala 2 (todas essas atividades são supervisionados por profissionais da instituição). $\mathrm{Na}$ Ala 1 nota-se uma maior interação entre os residentes, principalmente no horário das refeições, sendo o horário 
de maior confraternização o momento do café do meio da manhã e aos sábados na barbearia da instituição. Mesmo durante o dia alguns deles conversam, contam histórias, piadas e discutem sobre temas da atualidade. Este momento de interação entre eles, também ocorre durante o jogo de bilhar, de cartas, dominó e até mesmo enquanto assistem aos programas de televisão, tais como: futebol, jornal, novelas e programas de informação. Poucos têm o privilégio de sair da instituição sozinhos para passear, ir a algum lugar no bairro ou até mesmo ao centro da cidade. A independência e a autonomia são requisitos necessários para que isso aconteça.

As dificuldades na realização das atividades básicas da vida diária, são maiores nos idosos da Ala 2. Nesta ala, a necessidade da ajuda dos cuidadores é inevitável, todos precisam de ajuda no banho, a maioria para se vestir, alguns para se alimentar e a grande maioria faz uso de fralda. Também a maioria não se locomove sozinho, precisa de ajuda de um cuidador, dispositivo auxiliar ou da cadeira de rodas.

Na Ala 2 os idosos com maiores incapacidades permanecem o dia no refeitório sentados em cadeiras de rodas ou em poltronas, encostados à parede marginando o refeitório central da ala. Durante o dia fazem lá as suas refeições e às vezes participam de atividades na instituição. Mas, fora isso, a incapacidade obriga a que eles permaneçam ali, sem se poder deslocar. Nisso o quotidiano dessas pessoas se resume a assistir televisão, olhar o movimento e dormir nas poltronas, recostados ou debruçados nas mesas que estão à frente. Além deste aspeto, as incapacidades dificultam a interação social, favorecendo um estado imóvel de poucos movimentos, alguns com fácies apáticas e com olhares fixos, que só se movem quando acontece algum evento neste ambiente. Os que têm o cognitivo mais preservado escolhem o local onde ficar, ficando como "donos do lugar", ou seja, como se tivessem lugar marcado. Os que não estão restritos à cadeira de rodas, vão até à Ala 1 , frequentam o jardim, circulam pela Ala 2, tanto na área externa, como na interna. São aqueles que utilizam o movimento para realizar o essencial, ou pouco mais, como as atividades da vida diária, fumar, olhar algum acontecimento (alguém a passar, um carro a estacionar, etc.) e assim passam o dia.

$\mathrm{Na}$ Ala 2, os idosos têm cuidados prestados por profissionais qualificados ou por alunos devidamente supervisionados de vários cursos da área da saúde. No entanto, existe o temor entre os idosos da Ala 1 de um dia necessitarem permanecer na Ala 2. Para eles, esta ala é um ambiente que reflete a doença e a incapacidade. Mas, frequentemente os idosos que não precisam ficar mais na Ala 2, pelas melhoras da sua condição de saúde e da capacidade funcional, têm indicação de mudar para a ALA 1, mas preferem permanecer naquela ala. Sentem-se bem pelos cuidados prestados pelos profissionais da instituição e pelas amizades que porventura tenham feito, por isso preferem permanecer no local.

Ainda durante a observação participante destas rotinas, notaram-se três mudanças na vida quotidiana dos residentes da instituição, provocadas pelas alterações das doenças: a dependência, a perda da autonomia e a perda do controle percebido ou incontrolabilidade.

A dependência, já descrita nas rotinas anteriormente na observação participante, indica a necessidade de o indivíduo precisar de ajuda para realizar as atividades do quotidiano (Cortés et al., 2001).

A perda da autonomia é quando o indivíduo não tem liberdade individual, liberdade de escolha, vontade e autogovernação (Birren et al., 1991). A autonomia depende de três fatores: a confiança em si, a liberdade individual e a satisfação dos desejos (Agich, 2008). Segundo o autor, "a confiança em si refere-se à capacidade de prover as próprias capacidades" (p. 34). A pessoa realiza as atividades diárias associadas à perceção de bemestar. Outro fator da autonomia é a liberdade pessoal, que está ligada à preferência pessoal, escolha e decisão das pessoas. E por fim, a satisfação dos desejos, que é a "busca aparentemente incessante de satisfação de suas preferências, pois sem tal satisfação a própria autonomia é vista como inútil e vazia” (p. 35). 
O controle sobre o próprio corpo é um aspeto que está presente na consciência das pessoas que envelhecem, devido ao medo da dependência física e serem incapazes de suportar o tipo de atividades que as pessoas podem esperar que elas participem na velhice (Nettleton \& Watson, 1998). Contudo, segundo os autores, manter o controle do corpo é crucial para a vida quotidiana, onde a capacidade de ser percebido e aceito como um ator social competente requer certo nível de competências. Porém, ainda nesta discussão dos autores, o controle do corpo pode ser perdido devido às alterações orgânicas decorrentes das doenças. O controle percebido é entendido como um processo que ocorre de duas formas: o primeiro chamado de controle primário, que envolve as tentativas de mudar o ambiente, adaptando-o às necessidades da própria pessoa. O outro processo, denominado de controle secundário, leva a pessoa adaptar-se ao ambiente, através da passividade, retirada e submissão (Rothbaum et al., 1982). Os autores acrescentam que o controle secundário também pode ocorrer, após várias tentativas frustradas do controle primário. Alguns estudos ligam este tipo de controle, à incontrolabilidade. Portanto, a perda do controle percebido é quando o indivíduo deixa ter expetativa ou perceção de participar na tomada de decisões, escolhas, ou atos, a fim de obter consequências desejáveis e um sentido de competência pessoal em dada situação (Weinberg, 1995/1998; Rodin, 1990).

Kaufman (2011) num de seus livros aborda a questão da mobilidade: "Por que nos movemos?". No ponto de vista do autor, nos movemos para relaxar, para a realização das nossas atividades, na transição de uma atividade para a outra, na mudança de papel social, na mudança de status social, para um ou com um parceiro, ou ainda nos movemos para nos movermos, como numa caminhada ou num carro. No mesmo ponto de vista, Cott et al. (1995, p. 88) acrescentam que "o movimento permite mudar de posição, ir de um lugar para outro, explorar seu ambiente físico e social, procurar suas necessidades básicas, o alojamento, as companhias, o conhecimento e fazer suas escolhas".

Pudemos constatar na observação participante, que durante o quotidiano das pessoas idosas da instituição, o comprometimento da mobilidade física e espacial, é um fator que dificulta ou impede a realização de atividades e a participação social. Com o aumento da idade, a saúde declina e um número crescente de deficiências e de problemas são observados (Bell et al., 2013). Também se pode notar que o comprometimento da mobilidade está presente na vida quotidiana, conforme os resultados das entrevistas apresentados a seguir.

\section{Resultados das Entrevistas}

Nos resultados das entrevistas verificou-se a perda da liberdade, dependência física nas atividades básicas de vida diária e nas atividades instrumentais de vida diária, diminuição na ocupação, isolamento e dificuldade para dormir.

\section{A Perda da Liberdade}

Um sinal de liberdade é quando as pessoas têm movimentos amplos no tempo e espaço (Kaufman, 2011). Uma das características do corpo humano é a liberdade, mas, quando este é acometido por alguma incapacidade, essa liberdade fica ameaçada (Burgos, 2013). A perda da liberdade provocada pela doença também foi constatada em idosos institucionalizados, traduzida pelas sensações de o corpo estar "enrolado", "amarrado" e "preso" (Bispo, 2009, pp. 163-164).

(...) não tenho a liberdade, podia andar, passear e essas coisas (...) Fico mais preso, mais inseguro, mais com medo (E1). 


\section{Dependência Física nas Atividades Básicas e Instrumentais de Vida Diária}

As doenças crónicas podem levar a amplas repercussões na vida dos idosos institucionalizados, afetando a realização das atividades básicas da vida diária e as atividades instrumentais da vida diária (Lenardt et al., 2009). Segundo Guccione (2000/2002), nas atividades da vida diária, os idosos institucionalizados apresentam uma maior dependência, principalmente nas atividades de tomar banho, vestir e alimentar-se. Na pesquisa de Fernández e Casas (2012) realizada com 85 idosos dependentes, também constataram que as duas atividades da vida diária mais comprometidas, eram o banho e vestir. $\mathrm{Na}$ atividade de tomar banho, a diminuição na mobilidade articular dos membros superiores, a capacidade de preensão e a presença de tremor trará dificuldade no manuseio dos utensílios de banho e o alcance funcional de todas as partes do corpo. A dificuldade funcional nas tarefas de vestir e tirar a roupa, aparece pela diminuição da mobilidade articular, a instabilidade, a deformidade de membros superiores, por apraxia da sequência dos movimentos e na hemiparesia e hemiplegia. As alterações articulares podem impedir as atividades de vestir e de higiene que requerem colocar as mãos atrás da cabeça, nos glúteos e no ombro oposto (Sanches, 2006).

(...) interfere nos movimentos, por exemplo, fazer a barba, escovar os dentes, tomar banho (E8). Não posso trocar a roupa, não posso tomar banho sozinha (E16). Não posso calçar o tênis, se eu calçar o tênis, arruína mais ainda (E24). Quando eu vou pôr roupa, neste lado tenho mais facilidade, mas neste aqui é mais difícil, eu tenho que erguer o braço (E29). Tenho dificuldade para vestir a roupa. Pra vestir a roupa, a mão esquerda não ajuda (E32). Preciso de ajuda para tomar banho, para trocar a fralda, trocar a roupa. Tenho canseira quando falo (E36). $\mathrm{Na}$ alimentação, a dificuldade ocorre quando se tenta manejar adequadamente os utensílios para comer, como o copo, segurar a colher e o garfo, até mesmo ao realizar pressão com a faca para cortar ou untar (Sanches, 2006).

Já deixei cair o prato de comida. Eu pego um objeto assim e ela solta. A mão não segura (E9). A mão está adormecida, os dedos adormecidos, não enxergo, não consigo pegar nada (E11). Pego com esta daqui, porque a outra treme, derruba as coisas. A salada, um pedaço de carne, o arroz, tenho que pegar com esta (E21). Muito ruim, muito, muito ruim. Atrapalha quando a gente vai comer e beber (E30).

O idoso deve realizar determinados movimentos na cama necessários para conseguir conforto e segurança. Mover-se até à cabeceira da cama, sentar-se na cama e manter o equilíbrio para realizar atividades, tais como vestir e comer (Pérez-Brown et al., 2006). A limitação da mobilidade e a diminuição da força impedem que o idoso possa mover-se na cama (Sanches, 2006).

(...) à noite se eu for erguer o corpo pra subir na altura do travesseiro, eu faço com este lado aqui. Pra erguer mais as costas no travesseiro, tenho que fazer força com esse braço, mas é difícil. Quando vou levantar também, se eu fizer para o lado direito da cama, não adianta, porque aqui é pouca força no braço (E29).

Os participantes também relataram a dificuldade em agachar:

Se eu agachar, eu não levanto (E10).

A marcha normal depende da livre mobilidade das articulações, da ação muscular apropriada para a produção de força, além de um nível suficiente de capacidade para executar o trabalho, ou seja, condicionamento físico (Olney \& Culham, 1995/1998).

Estou com dificuldade nos braços e de andar, ainda não dá pra andar sozinha (E6). Eu não posso andar. Atrapalha no andar. Eu andava (...), andava dentro de casa andava bem e agora não posso andar (E7). Tenho dificuldade de andar. Estou arrasada de estar assim. Andar certinho, com o andador, eu tenho medo, sou medrosa, falta 
segurança mesmo (E17). Não ando, não dá para andar (E33). Eu não estou conseguindo andar (E34). A dor nas pernas impede de eu andar (E35).

"Se alguém está debilitado e preso à cadeira de rodas, então o acesso é limitado a superfícies favoráveis a este modo de locomoção. A cadeira de rodas altera a perspectiva da pessoa" (Agich, 2008, p. 203).

No momento não ando, depois da fratura não andei, só na cadeira de rodas. Só fico andando na cadeira de rodas no momento (E37).

A dificuldade de andar foi visível em alguns relatos, devido ao medo de cair:

Começa a doer as pernas, pra caminhar quase caio, seguro nessa muleta, a muleta resvala e não consigo firmar muito bem (E12). Traz medo, medo de morrer. Ficar sem poder andar, não posso andar de pressa, tenho medo de cair por causa do joelho (E22).

Nos idosos institucionalizados, é comum notar-se a dificuldade em utilizar as escadas, as queixas mais relatadas nos idosos são a fraqueza em membros inferiores, dor, a hemiplegia, tontura, desequilíbrio, o cansaço e outros fatores considerados como de risco de quedas. As doenças são fatores intrínsecos que contribuem para essa dificuldade na utilização das escadas (Kikuch \& Bispo, 2010). Subir e descer escadas pode converter-se em uma árdua tarefa pelo esforço que requer e pela dor provocada na flexão de todas as articulações para poder subir passo a passo. Os idosos correm o risco de cair por calcular mal o passo. Subir e descer escadas também gera quedas de forma frequente por ser uma atividade que requer uma coordenação precisa entre o sistema vestibular e a osteoarticular (Sanches, 2006).

Descer escada eu desço, agora subir (...) Se tiver que subir eu subo, mas é meio ruim, dá falta de ar (...). Na escada eu quase não subo, mas descer eu desço (E28).

A organização e limpeza da casa, o cuidado com a roupa e o uso de eletrodomésticos são as atividades principais que compõem o cuidado da casa (Sanches, 2006). Nos relatos dos participantes, notou-se a dependência física nas atividades instrumentais da vida diária:

Fazia muita coisa. Eu gosto de trabalhar na cozinha, sempre fui cozinheiro (E14). Pois é (...), a minha força agora (...), ainda carrego uma cadeira dessas, mas arrastando, lá da cozinha eu arrasto até aqui (E15).

Para as pessoas terem mobilidade nas áreas urbanas, necessitam ter um bom estado de saúde, em caso contrário, se apresentarem incapacidades, essa mobilidade estará severamente prejudicada (Bell et al., 2013).

Por causa da dor eu não posso andar, nem sair à rua por causa do perigo que é. Não se deve sair à rua não (E4).

Eu não faço mais nada, não tenho o que fazer. Desanimo de ir ao banco guardar dinheiro (E27).

A utilização do transporte público urbano ou de viagens mais longas apresentam algumas incomodidades aos passageiros, sendo exacerbadas naqueles que apresentam incapacidades funcionais:

Não posso ir a Londrina de Circular (autocarro). Eu o ano passado ia (E22). Eu gosto de viajar, ver minhas cunhadas, que ainda tenho duas vivas, eu gosto disso. Agora não, parei um pouco, dei uma maneirada, estou doente, doente sem poder fazer nada, vai fazer o que? (E5).

\section{Diminuição na Ocupação}

Verificou-se durante os relatos, onde a pessoa é incapaz de preencher seu tempo de maneira costumeira (McColl, 1995/1998). O trabalho que "é a execução de tarefas que exijam esforço mental e físico, tem como objetivo a produção de bens e serviços para atender às necessidades humanas" (Giddens, 2009/2012). 
Se tiver trabalhando tenho que parar, (...) não posso pegar o serviço, se eu pegar, começa a repuxar esta parte, começa a repuxar os nervos, começa a travar (E2). O dia que estou atordoada não posso sair de casa, não posso andar, tenho que ficar dentro de casa. Agora não trabalho mais (E18). Começa a doer aqui, que endurece tudo. Gostaria de fazer as coisas que eu fazia antes, fazia a roupa. O que eu gosto de fazer é crochê (E19). Às vezes pedem para eu fazer um serviço, aí falo: "não dá para eu ir, o senhor vai me desculpar, mas a coluna está atacada (E25). A doença atrapalha de tudo na minha vida, por exemplo, trabalhar eu não posso (E26).

Segundo Marcelino (2006), existem fatores que impedem a prática do lazer, denominadas "barreiras para o lazer". Dentre as várias barreiras citadas pelo autor as que podem afetar os residentes de uma ILPI, são as relacionadas à faixa etária e às limitações físicas e mentais.

(...) eu quero ler, escrever e fazer as coisas e agora não posso mais. Agora não posso mais ler e escrever (E20). (...) jogar bola, andar de bicicleta, nadar que nem eu nadava, passear, cantar, tocar violão que eu tinha aí, você vê (...) Abandonei tudo (E23).

\section{Isolamento}

O isolamento ocorre quando o indivíduo se torna incapaz de manter e participar normalmente das relações sociais (McColl, 1995/1998). Nos relatos de Moliner et al. (2008), as doenças também podem originar problemas sociais tais como a inatividade e a exclusão, que são respetivamente o oposto da atividade e da participação social. Na ideia do idoso institucionalizado, pode-se aproveitar o pensamento de Moragas (2004, p. 113): “a força física é menor, os estímulos psíquicos diminuem e a experiência ensina ao idoso que é mais difícil lutar contra o sistema do que se adaptar".

A sociedade muitas vezes discrimina os indivíduos pela cor da sua pele, pela cultura e pela etnia. Entretanto acontece o mesmo com as pessoas com doenças crónicas e com deficiências. Os sinais visíveis de doença ou por estarem numa cadeira de rodas, faz com que a sociedade os evite (Larsen, 2013a).

Conviver com isso pesa. Eu fico inseguro de dizer alguma coisa, alguém falar que você é um esquizofrênico, você é um paranoico (...). Então eu fico chateado com isso, me aborrece. Eu tenho dificuldade na comunicação (...) É difícil pelo fato de eu ter medo; “ah, você é inválido" (E3). Às vezes as pessoas falam: "o senhor só fica naquele buraco lá, não sai". Sair como? Eu rezo, fico doido pra não sair, não quero sair. Sair para passear é um sofrimento pra mim (E23). O problema que eu tenho é de estar sozinho. A tontura é forte (E31).

\section{Dificuldade em Dormir}

A dificuldade em dormir foi outro acontecimento exposto pelos entrevistados. O sono é um componente distinto e essencial do comportamento humano. Praticamente um terço de nossa vida é gasto dormindo. O sono é um estado reversível de desligamento da perceção do ambiente, com modificação do nível de consciência e de resposta aos estímulos internos e externos. É um processo ativo envolvendo múltiplos e complexos mecanismos fisiológicos e comportamentais em vários sistemas e regiões do sistema nervoso central (Moraes, 2012). O que acontece na vida quotidiana pode ter impacto sobre a nossa capacidade de dormir e a chance de ter uma boa noite (Nettleton, 2013).

Meio desanimado, a gente desanima, por causa da dor. Tenho dificuldade em dormir (...) (E4). Tem vezes que eu quero dormir, começo a tremer, aí perco sono (E13). 


\section{Considerações Finais}

Vimos neste estudo a importância da pesquisa etnográfica na área da saúde. Através da entrada em campo com a técnica da observação participante e das entrevistas abertas, conseguiu-se constatar as mudanças na vida quotidiana de pessoas que vivem numa instituição de longa permanência para idosos, provocadas pelo impacto da doença. Através da subjetividade do autor e dos participantes da pesquisa, verificou-se o efeito e a influência que a doença ocasiona na vida de cada indivíduo.

Antes do trabalho de campo, a descrição documental das características dos residentes da instituição, revelou aspetos importantes, tais como: em relação ao estado civil serem sozinhas, não terem filhos, viverem sozinhos antes da institucionalização, a causa da institucionalização por debilidade da saúde e dependência e perda da autonomia.

Durante o trabalho de campo, no momento da observação participante, foi verificado a dependência funcional, a perda da autonomia e a incontrolabilidade. Nos relatos dos participantes nas entrevistas, notou-se a perda da liberdade, a dependência física nas atividades básicas de vida diária e nas atividades instrumentais de vida diária, a diminuição na ocupação, o isolamento e a dificuldade para dormir. Pudemos constatar durante a observação participante e nos relatos das entrevistas, que o comprometimento da mobilidade se destaca com frequência durante a vida quotidiana das pessoas idosas da instituição.

Os resultados desta pesquisa são de grande relevância para os profissionais que atendem pessoas idosas visando a individualidade e subjetividade durante os cuidados. Neste sentido, as ações profissionais que estimulam e favorecem as capacidades físicas, mentais e sociais, podem diminuir as mudanças na vida quotidiana das pessoas idosas, provocadas pelo impacto da doença.

A pesquisa qualitativa necessita de mais estudos que investiguem sobre o impacto da doença nas pessoas idosas, devido à escassez deste tipo de estudos. Nesta abordagem podemos entender o impacto como efeito ou influência de um evento que pessoas tiveram como experiência. Na área do envelhecimento, este evento não ocorre só em instituições de longa permanência para idosos, mas também, na comunidade, em hospitais, nos centros de dia, no domicílio, na rua ou até mesmo durante alguma ação ou ocupação.

Agradecimentos | Acknowledgements: À instituição de longa permanência para idosos, à Universidade Pitágoras Unopar, à Irmã Maria José Oliveira, ao Professor Ruy Moreira da Costa Filho, à Professora Adriana de Paula Fontana Carvalho.

Conflito de interesses | Conflict of interest: Parte deste artigo foi apresentado no 9o Congresso Ibero-americano de Investigação Qualitativa, Lisboa. Parte deste artigo foi submetido a capítulo de livro ("O impacto da doença na vida cotidiana em pessoas idosas institucionalizadas", Editora Atena - Ponta Grossa, Brasil).

Fontes de financiamento | Funding sources: Coordenação de Aperfeiçoamento de Pessoal de Nível Superior (CAPES).

Contributos: NNCB: Revisão da literatura; Recolha, inserção e tratamento dos dados; redação do manuscrito; responsável pelo projeto de pesquisa e participação em todas as fases da pesquisa. VVSPC: Contributo na redação do manuscrito; Tratamento e discussão dos dados; Revisão da redação final do manuscrito. MM: Contributo na redação do manuscrito; Tratamento e discussão dos dados. LCF: Contributo na redação do manuscrito. TASF: Contributo na redação do manuscrito. FFG: Contributo na redação do manuscrito. TFF: Contributo na redação do manuscrito. FMM: Contributo na redação do manuscrito; Tratamento e discussão dos dados. RGCL: Contributo na redação do manuscrito; Tratamento e discussão dos dados. MHVBC: Contributo na redação do manuscrito; Tratamento e discussão dos dados; Revisão da redação final do manuscrito, orientação do projeto. 


\section{Referências}

Agich, G. J. (2008). Dependência e autonomia na velhice. Edições Loyola.

Barkan, S. E. (2012). Sociology: Comprehensive edition (Vol. 1.0.) https://2012books.lardbucket.org/books/sociologycomprehensive-edition

Barsaglini, R. A., \& Soares, B. B. N. S. (2018). Impactos de adoecimento de longa duração: experiência de adultos jovens com leucemia mieloide aguda. Ciências e Saúde Coletiva, 23(2), 399-408. https://doi.org/10.1590/141381232018232.15442017

Bell, D., Pokriefke, E., Risser, R., Biler, S., Šenk, P., Parkes, A., Stannard, J., Armoogum, J., Marin-Lamellet, C., Gabaude, C., Madre, J.-L., Alauzet, A., Monterde-i-Bort, H., \& Henriksson, P. (2013). Mobility patterns in the ageing populations (Work package 2; CONSOL - WP2 - Mobility Patterns in the Ageing Populations). https://bit.ly/3bTThRI

Bispo, N. N. C. (2009). O significado do estágio de fisioterapia numa instituição de longa permanência para idosos. Clube de Autores.

Birren, J. E., Lubben, J. E., Rowe, J. C., \& Deutchman, D. E. (1991). The concept the measurement of quality of life in the frail elderly. Academic Press. https://doi.org/10.1016/C2009-0-02653-1

Burgos, J. M. (2013). Antropología: uma guia para la existência (5a ed.). Albatros.

Bury, M. (1982). Chronic illness as biographical disruption. Sociology of Health \& Illness, 4(2), $167-182$. https://doi.org/10.1111/1467-9566.ep11339939

Calabrese, J. D. (2013). Ethnographic approaches to health experiences research. In S. Ziebland, A. Coulter, J. D. Calabrese, \& L. Locock (Eds.), Understanding and using health experiences: Improving patient care (pp. 28-38). Oxford University. https://doi.org/10.1093/acprof:oso/9780199665372.003.0003

Cortés, J. J. B., Calvo, M, H., \& Montalvo, J. I. G. (2001). Valoración integral del anciano: Instrumentos de evaluación. In F. B. Pareja, J. I. González-Montalvo, \& P. Martínez-Martín, (Eds.), Neurogeriatria: Temas fundamentales (pp. 3760). Aula Medica.

Cott, C. A., Finch, E., Gasner, D., Yoshida, K., Thomas, S., \& Verrier, M. (1995). The movement continuum theory of physical therapy. Physiotherapy Canada, 47(2), 87-95. https://bit.ly/2ASnlQr

Creswell, J. W. (2014). Investigação qualitativa e projeto de pesquisa: Escolhendo entre cinco abordagens (D. S. S. Mallmann da Rosa, Trad.) (3a ed.). Penso Editora. (Trabalho original publicado em 2012)

Dramé, M., Jovenin, N., Ankri, J., Somme, D., Novella, J.-L., Gauvain, J.-B., Bige, V., Colvez, A., Couturier, P., Heitz, D., Voisin, T., Wazières, B. D., Gonthier, R., Jeandel, C., Jolly, D., Saint-Jean, O., \& Blanchard, F. (2004). La fragilité du sujet âgé: Actualité - perspectives. Gerontologie et societe, 27(109), 31-45. https://doi.org/10.3917/gs.109.0031

Fernández, O. S., \& Casas, S. B. (2012). Caracterización de salud, dependencia, inmovilidad y riesgo de úlceras por presión de enfermos ingresados al programa de atención domiciliaria. Ciencia y Enfermeria, 18(3), 61-72. https://doi.org/10.4067/S0717-95532012000300007

Flick, U. (2009). Introdução à pesquisa qualitativa (3a ed.). Artmed \& Brokman.

Folstein, M. F., Folstein, S. E., \& McHugh, P. R. (1975). “Mini-mental state”: A practical method for grading the cognitive state of patients for the clinician. Journal of Psychiatric Research, 12(3), 189-198. https://doi.org/10.1016/00223956(75)90026-6

Giddens, A. (2012). Sociologia (A. Figueiredo, A. P. D. Baltazar, C. L. da Silva, P. Matos, \& V. Gil, Trad.; 6a ed.). Artmed. (Trabalho original publicado em 2009)

Gillespie, L., \& Petersen, S. (2012). Rituals and routines: Supporting infants and toddlers and their families. Young Children, 67(4), 76-77. https://bit.ly/3bUr50e

Guccione, A. A. (2002). O estado de saúde: estrutura conceitual e terminologia para o exame, avaliação e diagnóstico. In A. A. Guccione (Ed.), Fisioterapia geriátrica (2ª ed., pp. 105-113). Guanabara Koogan. (Trabalho original publicado em 2000)

Hayflick, L. (2007). Biological aging is no longer an unsolved problem. Annals of the New York Academy of Sciences, 1100 , 1-13. https://doi.org/10.1196/annals.1395.001 
Hammersley, M. (2018). What is ethnography? Can it survive? Should it? Ethnography and Education, 13(1), 1-17. https://doi.org/10.1080/17457823.2017.1298458

Hammersley, M., \& Atkinson, P. (2007). Ethnography: Principles in practice (3a ed.). Taylor \& Francis.

Kaufman, V. (2011). Rethinking the city: Urban dynamics and motility. EPFL Press.

Kikuch, E. H., \& Bispo, N. N. C. (2010). Fatores associados a quedas durante a utilização de escadas por idosos institucionalizados. UNOPAR Cientifíca, Ciências Biológicas e da Saúde, 12(2), 45-50. https://doi.org/10.21270/archi.v6i1.1784

Kottak, C. P. (2013). Um espelho para a humanidade: uma introdução à antropologia cultural (R. C. Costa, Trad.; 8a ed.). Penso. (Trabalho original publicado em 2012)

Larsen, P. D. (2013a). The illness experience. In I. M. Lubkin, \& P. D. Larsen (Eds.), Chronic illness as biographical disruption or biographical disruption as chronic illness reflections on a core concept (8a ed., pp. 23-45). Jones \& Bartlett.

Larsen, P. D. (2013b). Chronicity. In I. M. Lubkin \& P. D. Larsen. (Eds.), Chronic illness as biographical disruption or biographical disruption as chronic illness reflections on a core concept (8a ed., pp. 3-22). Jones \& Bartlett.

Le Breton, D. (2011). Antropologia do corpo e modernidade. Editora Vozes. (Trabalho original publicado em 2003)

Lenardt, M. H., Michel, T., \& Tallmann, A. E. C. (2009). A condição de saúde de idosas residentes em instituição de longa permanência. Cogitare Enfermagem, 14(2), 227-236. https://doi.org/10.5380/ce.v14i2.15608

Marcelino, N. C. (2006). Estudos do lazer (4a ed.). Autores Associados.

Martins, G. A., \& Theóphilo, C. R. (2009). Metodologia da investigação científica para ciências sociais aplicadas (2a ed.). Atlas.

Mattos, C. L. G. (2011). A abordagem etnográfica na investigação científica. In C. L. G. Mattos, \& P. A. Castro (Eds.), Etnografia e educação: conceitos e usos (pp. 49-83). EDUEPB.

McColl, M., Rosenthal, C., \& Rowe, W. K. (1998). Deficiências na velhice. In B. Pickles, A. Compton, C. Cott, J. Simpson, \& A. Vandervoort (Eds.), Fisioterapia na terceira idade (pp. 325-337). Santos Livraria Editora. (Trabalho original publicado em 1995)

Meire, P. (2000). La vulnérabilité des personnes âgées [Vulnerabilidade das pessoas idosas]. Louvain Médical, 119(5), S221-S226.

Minayo, M. C. S. (2007). O desafio do conhecimento: pesquisa qualitativa em saúde (10ạ ed.). Hubitec/Abrasco.

Moliner, P., Ivan-Rey, M., \& Vidal, J. (2008). Trois approches psychosociales du vieillissement. Identité, catégorisations et représentations sociales [Três abordagens psicossociais para o envelhecimento. Identidade, categorizações e representações sociais]. Psychologie \& NeuroPsychiatrie du Vieillissement, 6(4), 245-257.

Moraes, E. N. (2012). Atenção à saúde do idoso: aspetos conceituais. Organização Pan-Americana da Saúde (OPAS). https://bit.ly/2LU2ILn

Moragas, R. M. (2004). Gerontologia social: envelhecimento e qualidade de vida (2a ed.). Paulinas.

Nagi, S. (1964). A study in the evaluation of disability and rehabilitation potential: concepts, methods, and procedures. American Journal of Public Health, 54(9), 1568-1579. https://doi.org/10.2105/ajph.54.9.1568

Nettleton, S. (2013). The sociology of health and illness (3a ed.). Polity.

Nettleton, S., \& Watson, J. (1998). Introduction. In S. Nettleton \& J. Watson (Ed.), The body in everyday life (pp. 1-23). Routledge.

Olney, S. J., \& Culham, E. G. (1998). Alterações da postura e da marcha. In B. Pickles, A. Compton, C. Cott, J. Simpson, \& A. Vandervoort (Eds.), Fisioterapia na terceira idade (pp. 81-94). Editora Santos. (Trabalho original publicado em 1995)

Pérez-Brown, D., Ayuso, D. M. R., Garlito, P. A. C., Miralles, P. M., Álvarez, A. A., \& Sánchez, A. I. C. (2006). Herramientas para la evaluación de las actividades de la vida diária. In P. M. Miralles \& D. M. R. Ayuso (Eds.), Actividades de la vida diária (pp. 77-133). Editorial Elsevier Masson.

Pole, C., \& Hillyard, S. (2016). Doing fieldwork. Sage. 
Rodin, J. (1990). Control by any other name: Definitions, concepts, and processes. In J. Rodin, C. Schooler, \& K. W. Schaie (Eds.), Self-directedness: Cause and effects throughout the life course (pp. 1-17). Lawrence Erlbaum Associates.

Reeves, S., Kuper, A., \& Hodges, B. D. (2008). Qualitative research methodologies: Ethnography. BMJ, 337, a1020. https://doi.org/10.1136/bmj.a1020

Royer, A. (1998). Life whit chronic illness: Social and psychological dimension. Praeger.

Rothbaum, F., Weisz, J. R., \& Sneyder, S. S. (1982). Changing the world and changing the self: A two-process model and perceived control. Jornal of Personality and Social Psychology, 42(1), 5-37. https://bit.ly/2XouWO6

Sampieri, R. H., Callado, C. F., \& Lucio, M. P. B. (2013). Metodologia da pesquisa (5a ed.). McGraw Hill \& Penso.

Sanches, A. I. C. (2006). Actividades de la vida diária em geriatria. In P. M. Miralles \& D. M. R. Ayuso (Eds.), Actividades de la vida diária (pp. 349-379). Masson.

Spradley, J. P. (1980). Participant observation. Holt, Rinehart and Winston.

Sugahara, G. T. L. (2005). O perfil do idoso brasileiro. Kairós, 8(2), 51-75. https://bit.ly/3cRpfPg

Weinberg, L. E. (1998). Aplicações da sensação de controle e da dependência adquirida. In B. Pickles, A. Compton, C. Cott, J. Simpson, \& A. Vandervoort (Eds.), Fisioterapia na terceira idade (pp. 138-147). Editora Santos. (Trabalho original publicado em 1995) 